Profesora de literatura hispanoamericana de la Universidad de Alicante. Ha centrado su investigación en el mundo colonial y especialmente en la producción teatral mexicana, a la que ha dedicado, además de diversos artículos, su monografía El teatro evangelizador. Sociedad, cultura e ideología en la Nueva España del Siglo XVI (Bulzoni, 1999). En los últimos años ha dirigido su investigación hacia la Crónica de Indias y su recuperación en la literatura contemporánea, ámbito al que corresponde su última publicación, Abel Posse: de la crónica al mito de América (Universidad de Alicante, 2004).

\title{
DAIMÓN DE ABEL POSSE: HACIA UNA NUEVA CRÓNICA DE AMÉRICA
}

\author{
BEATRIZ ARACIL VARÓN
}

Es evidente que la historia se reescribe, y no para neAbel Posse en Luis Sáinz de Medrano (coord.), La Semana de Autor sobre Abel Posse, Madrid, Ediciones de Cultura Hispánica, 1997, pág. 83.

2

Término acuñado para la cultura náhuatl por Miguel León-Portilla en Crónicas indigenas. Visión de los vencidos, Madrid, Historia 16,1985 [ $1^{\circ}$ ed. 1959] y ampliamente recogido por diversos autores respecto a otros contextos de la América indígena.

3

Véase Tzvetan Todorov, La conquista de América. El problema del otro, Madrid, Siglo XXI, 1989.

4

Véase Beatriz Pastor, Discursos narrativos de la Conquista, Santiago, Casa de las Américas, 1983.

5

Trilogía que se completa con Los perros del paraíso (1983), sobre Cristóbal Colón y el Descubrimiento, y la anunciada novela Los heraldos negros, sobre las misiones jesuíticas del Paraguay, todavía no publicada.

6

En 1968 Posse presentó al premio Planeta su primera novela, Los bogavantes (que fue prohibida por la censura franquista y no fue publicada hasta dos años más tarde) y en 1970 publicó La boca del tigre, III Premio Nacio-

Daimón de Abel Posse: hacia una nueva crónica de América

BEATRIZ ARACIL VARÓN

gar lo que ya ha sido escrito, sino para completarlo (...); los escritores de América Latina hemos ayudado a dar una nueva visión, a hacer más aceptable lo contado, porque hemos fraguado imaginativamente la crónica, pero sobre todo hemos releído para reescribirla1.

Con estas palabras describía el escritor argentino Abel Posse en 1995 la aportación de los escritores latinoamericanos a esa ardua pero necesaria tarea, aún inacabada, de revisión del amplio y diverso corpus textual que conforma la Crónica de Indias. En unas décadas en las que la crítica literaria ha hablado de «visión de los vencidos»², del «problema del otro» ${ }^{3}$ o del «discurso del fracaso» ${ }^{4}$ como nuevos enfoques capaces de propiciar un acercamiento más adecuado a la realidad diversa y compleja de la Crónica, la creación literaria ha contribuido también a esa tarea de «reconstrucción», de relectura desde una perspectiva nal en Argentina. El propio autor, sin embargo, ha definido esta tercera novela como la iniciadora de una nueva forma de escritura, llegando a afirmar en una entrevista concedida a Silvia Pites: «...me considero un escritor múltiple. Comencé mi carrera literaria escribiendo poesía, he escrito siete novelas, también escribo en diarios y revistas, pero mi verdadero 'yo' literario se logra en Daimón y Los perros del paraíso» (Silvia Pites, «Entrevista con Abel Posse», Chasqui, Williamsburg, VA. noviembre 1993, pág. 126).
7

En España por esas fechas encontramos ya títulos destacados como Lope de Aguirre de Gonzalo Torrente Ballester (1941), Yo, demonio, de Elías Amézaga (1953) o La aventura equinoccial de Lope de Aguirre, de Ramón J. Sénder (1968).

8

La fascinación de Uslar Pietri por ese "monstruoso conquistador" ya le había llevado a escribir un relato anterior, «El fuego fatuo", y se manifestaría asimismo en su ensayo "El peregrino». múltiple, con unas obras que se proponen, como explica Posse, reescribir la Crónica, desentrañar las múltiples caras de una América plural que se esconden bajo la «historia oficial» (esa «Historia de lo grandilocuente, lo visible», como la define Posse), imaginar lo que los cronistas no quisieron o no se atrevieron a expresar, o lo que hubieran descrito los que no tuvieron siquiera la oportunidad de acceder a la escritura.

La publicación en 1978 de Daimón, la primera novela de su «Trilogía del Descubrimiento» ${ }^{5}$, inicia la fundamental contribución de Abel Posse a esta tarea de reescritura de la Crónica que es asimismo una tarea de descubrimiento de su verdadero «yo» literario, más allá de los ensayos que suponen sus novelas anteriores ${ }^{6}$.

Aunque se habían escrito ya otras obras sobre el tema ${ }^{7}$, la figura del conquistador Lope de Aguirre contaba entonces con dos referentes básicos: la recreación perfectamente documentada del personaje de Aguirre que había realizado el venezolano Arturo Uslar Pietri en El camino de El Dorado (1947), novela histórica en la línea de reflexión comprometida en torno a la historia americana que caracteriza al autor ${ }^{8}$, y la personalísima versión cinematográfica Aguirre, la cólera de Dios (1972) con la que Werner Herźog, entreverando diversas expediciones (en especial la de Orellana y la de Orsúa) en una nueva búsqueda de El Dorado, había dado a conocer al mundo a este personaje convertido en símbolo de la locura a la que conduce el deseo de poder y de fama.

Posse comparte con ambos creadores la atracción por este hombre que encarna el la- 
do más terrible de la conquista; como él mismo ha explicado:

Cuando yo elegí el personaje de Lope de Aguirre me pareció que era un personaje fascinante, y que yo podía rehabilitar la barbarie de Aguirre, la barbarie maravillosa de España, la barbarie que termina con una aventura desopilante y genial, aunque monstruosa?.

Su propuesta, sin embargo, se desmarca de la de los autores anteriores por su inscripción en unas coordenadas estéticas y políticas absolutamente distintas que él mismo explica:

Este personaje me pareció tan descomunal que decidí que tenía que seguir viviendo, porque esa impronta anárquica y salvaje es la que permaneció en América (...). Los dictadores de América son, de alguna manera, ese Lope de Aguirre, y yo traté de que ese personaje tuviera dos vidas: la suya real y otra que, mediante sucesivas reencarnaciones, lo lleva hasta el siglo XX. Ese ha sido mi esfuerzo y mi intento, el de utilizar a este personaje como símbolo de los diversos avatares de la vida y de la historia americana ${ }^{10}$.

En la novela de Posse la rebelión de Aguirre no es el tema, sino el punto de partida: Aguirre «regresa» de entre los muertos para organizar una nueva expedición, convirtiéndose en el hilo conductor de una obra que revisa lo que fue el descubrimiento y la conquista, pero también, en una concepción cíclica del tiempo, recorre cinco siglos de la historia de América. Desde el punto de vista literario, nos encontramos, como ha explicado Luis Sáinz de Medrano, ante «un ejercicio de libertad mucho más radical» que el de otros autores en el manejo del personaje ${ }^{11}$. Esta nueva visión / versión de Lope de Aguirre asume en buena medida las nuevas propuestas en torno al tratamiento de la materia histórica en la novela que definen ese "género» (si podemos llamarlo así) que Seymour Menton ha acuñado con el término de «nueva novela histórica latinoamericana»12, siendo, tal vez, su principal acierto el hecho de abordarlo por primera vez desde una perspectiva «bajtiniana» (para continuar con los planteamientos del Menton respecto a este tipo de novela) que hace uso de la parodia, la hipérbole, la befa, con una intención claramente desmitificadora. Pero, como apunta el propio Posse en la cita anterior, es imposible entender la elección del persona-

je, la concepción de la novela e incluso los recursos literarios citados sin acudir al contexto político más inmediato; explica Teodosio Fernández que

Cuando Posse publicó Daimón, en 1978, el panorama había cambiado notablemente. Los años setenta supusieron para Argentina el regreso de Perón, en 1973, y luego el gobierno militar que a partir de 1976 acentuó el clima de represión y violencia compartido por los demás países del cono sur ${ }^{13}$. Los escritores argentinos supervivientes hubieron de callar, de exiliarse o de buscar fórmulas narrativas capaces de evitar la censura y la autocensura. La novela histórica fue una de las posibilidades, en un momento en que el género empezaba a mostrar en Hispanoamérica una gran vitalidad. Daimón y Los perros del Paraíso (...) fueron las contribuciones de Posse al desarrollo de sus modalidades más novedosas ${ }^{14}$.

No es mi propósito insistir aquí en un aspecto sobre el que se han realizado ya algunas valiosas aportaciones críticas como es el de la contribución de Abel Posse al conjunto de la creación literaria en torno a la figura de Lope de Aguirre ${ }^{15}$, ni tampoco en su vinculación (aunque serán inevitables las referencias) con esa «nueva novela histórica latinoamericana» de la que Daimón y, sobre todo, Los perros del paraíso han sido considerados claros ejemplos $^{16}$. Mi interés se centra en Daimón como novela que presenta ya todos los componentes que van a definir el acercamiento del escritor argentino al periodo histórico que refleja la Crónica de Indias en su producción nove-

9

Posse en La Semana de Autor sobre Abel Posse, op. cit., pág. 77.

10

Ibidem, págs. 77-78.

11

Véase Luis Sáinz de Medrano, "Abel Posse y la búsqueda de lo absoluto", Anales de Literatura hispanoamericana, Madrid, Universidad Complutense, nº 21,1992, pág. 470.

12

Véase Seymour Menton, La nueva novela histórica de
América Latina, 1979-1992, México, Fondo de Cultura Económica, 1993.

13

Recordemos que la escritura de Daimón coincide con la dictadura de Videla en Argentina (1976-1981), pero también con la de Pinochet en Chile (1973-1990), Stroessner en Paraguay (1954-1989) y Bordaberry en Uruguay (19731976).

14

Teodosio Fernández en La Semana de Autor sobre Abel Posse, op. cit., pág. 31 .
15

Pueden consultarse a este respecto, entre otros, los trabajos de Juana Martínez Gómez, «Lope de Aguirre: historia y ficción", en AA. W, Las relaciones literarias entre España e Iberoamérica, XXIII Congreso del Instituto Internacional de Literatura lberoamericana, Madrid, Universidad Complutense, 1987, págs. 673679 , Ingrid Galster, «íLoco o libertador? La imagen de Aguirre en la historiografía y la ficción: un proyecto de investigación", en Karl Kohut (ed.), De conquistadores y conquistados. Realidad, justificación, representación, Frankfurt am Main, Vervuert, 1992, págs. 256-271 $y$ «El conquistador Lope de Aguirre en la nueva novela histórica", en Karl Kohut (ed.), La invención del pasado: la novela histórica en el marco de la postmodernidad, Frankfurt-Madrid, Ed. Iberoamericana, 1997, págs. 196204 ○ Antonio Ángel Usábel González, "Lope de Aguirre: la dominación del rebelde», en La novela histórica hispanoamericana: desde 1931 hasta nuestros dias, Universidad Autónoma de Madrid, 2000 (tesis doctoral), págs. 322-440.

\section{6}

Cf. especialmente Amalia Pulgarín Cuadrado, Metaficción historiográfica: la novela histórica en la narrativa hispánica postmodernista, Madrid, Fundamentos, 1995, págs. 57-106 y Menton, La nueva novela histórica de América Latina, op. cit., págs. 102-128.

Daimón de Abel Posse: hacia una nueva crónica de América

BEATRIZ ARACIL VARÓN 


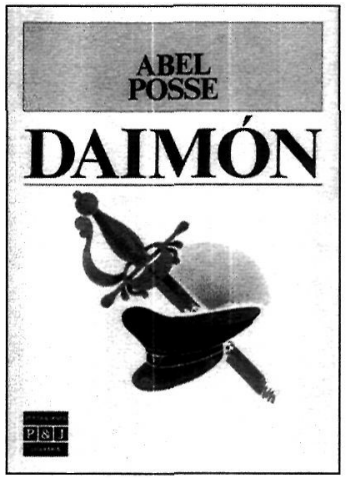

17

Por supuesto, la comparación entre las tres novelas que abordan este asunto es algo presente ya en la bibliografía sobre el autor (cf. La Semana de Autor sobre Abel Posse, op. cit., en especial las aportaciones de García Ramos en págs. 74-76); mi intención, sin embargo, se sitúa más en la línea que plantea Sáinz de Medrano respecto a esta novela (y la siguiente) en relación con el conjunto de la novelística de Posse, es decir, el análisis de Daimón como obra generadora de un tipo de discurso que va a reiterarse de alguna forma en creaciones posteriores.

18

La novela, con un importante éxito entre la crítica, obtuvo el premio Rómulo Gallegos en 1987.

19

Posse en La Semana de Autor sobre Abel Posse, op. cit., pág. 63.

\section{0}

Publicado en las Actas del Simposio Utopías del Nuevo Mundo, Praga, Charles U., 1993, págs. 258-265 y en Kohut, De conquistadores y conquistados, op. cit., págs. 249-255 (de donde se cita en el presente artículo).

21

Ibidem, pág. 249.

22

Ibidem, pág. 253.

23

Abel Posse, El largo atardecer del caminante [1992], Buenos Aires, Emecé, 1994, pág. 228.

24

Ibidem, pág. 33.

Daimón de Abel Posse: hacia una nueva crónica de América

BEATRIZ ARACIL VARÓN

lística posterior ${ }^{17}$. Mientras Daimón aborda el problema de la conquista a través de la figura del traidor Aguirre, en la ya citada novela Los perros del paraíso (1983), que supone la indiscutible consagración del autor ${ }^{18}$, Posse ofrece una nueva versión del Descubrimiento de América en la se entremezclan las perspectivas del propio Cristóbal Colón (quien se presenta como un judío converso obsesionado por la búsqueda del Paraíso), los Reyes Católicos (símbolos del poder y la violencia de todo imperio) y los propios indígenas, a través de las «delegaciones» inca y azteca que, en la primera parte de la novela, estudian una posible conquista del continente europeo. Por su parte, $E l$ largo atardecer del caminante (1992), analizada ampliamente en este mismo volumen por Luis Sáinz de Medrano, plantea de nuevo el tema de la conquista, pero a través del «gran personaje moral» de ésta, Alvar Núñez Cabeza de Vaca, quien, ya en sus últimos años, en Sevilla, recuerda los hechos que marcaron su vida en América y escribe una nueva crónica que corrige y amplía sus crónicas oficiales (Nanfragios y Comentarios). Se trata, en definitiva, de «una forma de compensar las visiones y las interpretaciones», como explica el propio Pos$\mathrm{se}^{19}$, que hace que esta obra, aun sin pertenecer a esa proyectada trilogía todavía inacabada, complete junto a las dos anteriores un cuadro diverso con el que Abel Posse busca desmentir la versión que nos dio la historia oficial de ese periodo fundacional de la realidad americana.

\section{EL DESCUBRIMIENTO DE LA HISTO- RIA}

Si hay un aspecto que define el tratamiento de la materia histórica en Daimón, como en las novelas posteriores de Posse sobre el descubrimiento y la conquista, es sin duda la necesidad del autor de reescribir un periodo histórico que ha sido escrito por los vencedores. Esta preocupación, vinculada a los preceptos generales de la nueva novela histórica, es en

25

Posse, «La novela como nueva crónica de América», op. cit., pág. 254.

\section{6}

Caballero Bonald en La Semana de Autor sobre Abel Posse, op. cit., pág. 28. realidad un rasgo esencial en un escritor que ha hecho de las relaciones entre la historia y la literatura el centro de toda su producción novelística. El propio Posse, en un artículo titulado «La novela como nueva crónica de América. Historia y mito ${ }^{20}$, señalaba ya cómo «en la gran literatura latinoamericana son excepción las obras que no surgen en relación a preocupaciones vinculadas a nuestra historia» ${ }^{21} \mathrm{y}$, concretamente al referirse a ese periodo fundamental del descubrimiento y la conquista, explicaba:

Nuestra literatura llegó casi a los umbrales de este siglo intoxicado por la «historia oficial» de la Conquista (...). Fueron los poetas y novelistas quienes lanzarían sus carabelas de papel para des-cubrir la versión justa (...), los que ajustaron el disparate de la historia imperial22.

La historia oficial nos ha ofrecido una versión falseada de la realidad porque, como dirá Alvar Núñez en El largo atardecer del caminante, «la misma Historia, con mayúscula, es un hecho criminal» ${ }^{23}$, pero, como su personaje, Posse sabe que, "para bien o para mal, la única realidad que queda es la de la historia escrita» ${ }^{24}$. Hay que volver, pues, al texto de la Crónica, pero no con las limitaciones del historiador, sino con la libertad del autor literario; una libertad que lleva a Posse a «usar la historiografía, para a veces negarla, modificarla, reinterpretarla» ${ }^{25}$ y que le permite ese continuo juego con el documento que va a encontrar su máxima expresión en Los perros del paraíso. Sobre esta obra decía Caballero Bonald que el autor se había propuesto «desarticular el engranaje de algunas viejas crónicas para volverlo a montar según unas sorprendentes instrucciones de uso» ${ }^{26}$. En realidad esta actitud se inicia ya con Daimón, novela en la que se entremezclan fragmentos de crónicas españolas e indígenas, se incluyen datos ficticios que pueden parecer históricos o se presentan datos históricos, incluso citas textuales, en contextos que nos hacen dudar de su autenticidad, como ocurre al principio de la obra cuando la pretendida «barbarie» indígena que muestra el hermoso poema de Nezahualcóyotl contrasta brutalmente con la «civilizada» alusión de Cristóbal Colón a la indecencia de dos niñas indígenas, perteneciente efectivamente a su famosa Carta de Jamaica $^{27}$. 
Este libre manejo del documento se vincula a toda una reflexión sobre la escritura que en Los perros del paraíso va a reflejarse sobre todo en el juego entre el diario secreto y el diario oficial de Colón y en El largo atardecer del caminante se convierte incluso en eje estructurador de la obra (ya que el protagonista se enfrenta a sí mismo a través de la revisión de su propia escritura, de la posibilidad de confirmar, corregir o ampliar lo escrito), pero, curiosamente, en Daimón nace de la propia obsesión de Aguirre, como personaje histórico, por la palabra escrita. Posse ha sabido captar desde el comienzo mismo de la novela la preocupación por el poder de la escritura de ese conquistador analfabeto cuya acción más famosa es, casi de forma paradójica, haber dirigido a Felipe II una carta de rebelión a la Corona. Cuando el Aguirre de Posse dicta a Blas Gutiérrez una segunda carta en la que anuncia al rey el inicio de su nueva jornada, le advierte: «anota con la mejor letra que encuentres (...). Pones así como te digo, sin cambiar ni coma (...). Debajo de mi nombre pones El Peregrino El Traidor El Rebelde, todo así como te dije, con mayúscula» ${ }^{28}$; y, más de siglo y medio después, utilizará semejantes términos cuando dicte la que informe a Felipe $\mathrm{V}$ de la continuidad de su «jornada en rebeldía» ${ }^{29}$. El Escribano adquiere así un valor destacado para el protagonista, pero también para la novela misma, al asumir el papel del autor literario. «Eres un tonto -dice Aguirre-. Eres de los de la raza de los que nos cuentan la vida en lugar de vivirla..., un pálido! ¡Pero no sé qué haría sin ti! ¡Eres el único que va comprendiendo algo de las cosas...! $!^{30}$.

\section{CONQUISTADORES Y CONQUISTA- DOS}

Escribir es para Posse, como para Blas Gutiérrez, intentar comprender, y ello supone en ocasiones desmentir, desmitificar. Reescribir la Historia es de algún modo «poner en orden los valores», lo que significa, respecto al hecho de la conquista, abordar «el choque fundamental entre la cultura de los conquistadores y los conquistados, choque que proviene del intento de imponer la una sobre la otra ${ }^{31}$. Por ello, en su deseo de descubrir la Historia, Abel Posse realiza en Daimón una evidente crítica a la conquista española como forma de imposición, como ejercicio de poder que se va a desarrollar a su vez, desde nuevas perspectivas, en Los perros del Paraíso y en El largo atardecer del caminante. Hay en sus novelas una denuncia de los abusos, de la ambición de los conquistadores. «Alguna vez se me acusó de reiterar la leyenda negra -explicaba con cierta ironía el autor argentino en una entrevista realizada en 1988-. Me acusaban de haber sido demasiado crítico con España y yo creo que emerge del texto mismo que en ningún momento tengo o he tenido resentimiento en contra de los personajes españoles. Tengo cariño por ellos aunque hayan sido monstruos» ${ }^{32}$. Recordemos que es precisamente ese carácter «monstruoso» el que había llevado al autor a elegir a Aguirre como protagonista de su novela, pero también el que le hizo pensar en el personaje como un daimón. Cuando en una nota a Los perros del paraíso se refiera también a los Reyes Católicos como daimones, se entenderá en toda su complejidad el motivo que lleva al autor a elegir el término incluso como título del libro; el daimón no es sólo un ser inmortal, es también un ser inmoral que ejerce el poder y la violencia:

En la angeología musulmana hay una clara referencia a esta categoría de ángeles que invaden la Tierra, en retorno germinativo, devueltos por la ira de un dios acosado por la indiscreta pasión cognoscitiva del humano. El angelos es sustancialmente el mensajero (...): en su forma menos sofisticada y más «humana», asumen el carácter de daimones y de héroes (...). Casi unánimemente los angeologistas convienen en la terribilidad $e$ insolencia de estos seres que moran al margen del código cristiano: no necesitan salvarse. No necesitan ni fe, ni esperanza, desconocen la caridad. Probablemente les repugne la piedad. Sólo se atienen a las leyes de su misión ${ }^{33}$.

Aunque volveré más adelante a la decisión del autor de crear un personaje que «tenía que seguir viviendo» ${ }^{34}$, me interesa ahora destacar cómo ese ser «descomunal», «monstruoso» simboliza un proceso de imposición cultural en América que sustituye el «estar», la existencia en armonía con la Naturaleza, por el «hacer» y el «ser», que oprimen y destruyen al hombre. La conquista es para él una forma de ejercer el poder, pero el propio Aguirre olvida que «todo poder, inclusive el suyo, siempre nace de la infamia, de
28

Daimón, págs. 22-23.

29

Ibidem, pág. 84

30

Ibidem, págs. 74-75.

31

Abel Posse en La Semana de Autor sobre Abel Posse, op. cit., pág. 105.

32

Pites, «Entrevista con Abel Posse», op. cit., pág. 127.

33

Los perros del paraíso, [1983], Barcelona, Plaza \& Janés, 1987, nota del autor, pág. 64.

34

Posse en La Semana de Autor sobre Abel Posse, op. cit., pág. 77.

Daimón de Abel Posse: hacia una nueva crónica de América BEATRIZ ARACIL VARON 
Véase Pites, «Entrevista a Abel Posse», pág. 124.

\section{6}

Los perros del paraíso, pág. 201.

37

Daimón, pág. 88.

38

Ibidem, pág. 196. la usurpación», e incluso él mismo será víctima de la violencia ejercida por nuevas formas de opresión hacia el final de la novela.

Abel Posse ha explicado en varias ocasiones cómo su obra reflexiona en torno al poder y la violencia de la conquista, poder y violencia que emanan del Imperio y se manifiestan en América en su vertiente militar y religiosa. La crítica del autor a ambas formas de poder se refleja en Daimón a través de dos personajes: Carrión, el verdugo que acabará siendo coronel (cuyo nombre aparece de nuevo en Los perros del paraíso como el del sargento que asiste al coronel Roldán) y Torres, el cura que alcanza la dignidad de obispo. Podría parecer contradictorio que la definición del daimón se realice desde la ausencia de los conceptos cristianos de fe, esperanza y caridad y, sin embargo, la Iglesia aparezca en esta y en las siguientes novelas como una institución opresora, aliada a los violentos; en realidad tal contradicción no existe: para el autor, el continente americano no ha conocido la religión cristiana, sino la religión católica imperial que nace del reinado de los Reyes Católicos ${ }^{35}$. Estas ideas, que se desprenden de forma más velada de las reflexiones de Alvar Núñez en torno a las consecuencias de la conquista, se plasman de forma contundente en Los perros del paraíso, en especial a través del episodio clave del «golpe de Estado» que pone fin al disfrute del Paraíso, en el que, tras el «patético» discurso del coronel Roldán, «se dirigieron todos al espacio de la proyectada catedral y ante la cruz-horca entonaron un emocionado Te Deum» ${ }^{36}$.

Habrá que señalar, en cualquier caso, que tampoco el cristianismo como religión goza del favor del autor. Abel Posse se ha referido también a la «guerra de dioses» que se libró de forma paralela a la guerra humana de la conquista, insistiendo en cómo fue la concepción judeo-cristiana de sufrimiento y de culpa la que, al triunfar sobre la concepción cósmica y metafísica de los indígenas, les negó para siempre el acceso a la felicidad. Es éste un aspecto que se muestra asimismo por primera vez en Daimón:

Algunos caciques, ex-amautas, brujos (malamente ejecutados por mano de Aguirre y su gente) aprovechaban para dar soga a su despecho: «¿Has visto, Lope? ¿Qué queda de vuestro cristianismo? Mejor hubiera sido que no hubierais venido a salvarnos. iJa!
¡Haz que nos devuelvan nuestros dioses; tan sólo así habrá paz, no te hagas ilusiones, hermanito! ¡Eran verdaderos nuestros dioses: nunca hubieran enseñado a malgastar la vida en una cruz! $\aleph^{37}$.

Hay en Abel Posse, pues, una crítica al poder, a la violencia, a la religión de los conquistadores que se completa además con un intento de dar voz al verdadero hombre americano, al indígena oprimido y marginado por el Imperio español y por las sucesivas formas de poder en América. El esfuerzo por mostrar la «visión de los vencidos» se refleja en toda la primera parte de Daimón («La epopeya del guerrero») a través de la inclusión en cada capítulo de una crónica de la conquista hecha por los propios indígenas. En un ejercicio de intertextualidad, las palabras del narrador se entremezclan con fragmentos de textos originales pertenecientes al Chilam Balam, los Cantares mexicanos o los Anales Cakchiqueles. Esta «crónica» de la conquista que corre paralela a los hechos protagonizados por Aguirre tiene su correlato, ya en la segunda parte, en el Congreso al que Aguirre acude, ya en el siglo $\mathrm{XX}$, para encontrarse con «todas las desdichas de los despojados»; los «vencidos» son ahora, además de los indígenas, los gauchos o la $\mathrm{Na}$ turaleza. La crítica se hace de nuevo palpable, a pesar de quedar revestida por ese humor irónico que recorre toda la novela:

La información que se presentaba era sabida por todos. Algunos delegados se demoraban en estadísticas (forma de la retórica prestigiosa y aritmética) con la minucia de delegados de Amnesty International.

El cacique de Tapajoz, Nurandaluguaburabara, supo sintetizar el estado de las cosas: «Los blancos tienen máuseres, ferrocarriles, cardenales, aguardiente, sifilis, biblias, geógrafos, perros, portugueses, prostitutas, dólares, espejitos, Comercio Exterior, capangas, capataces, Sociedad de Naciones, zapatos, suero antiofídico, cigarrillos rubios, Universidad, predicadores yankees, teodolitos y, sobre todo, coroneles amaestrados». Todo estaba dichos8.

La interpolación de textos originales indígenas volverá a caracterizar la escritura de Los perros del paraíso, obra en la que, sin embargo, la ironía presente en la imaginada reunión entre incas y aztecas antes de la llegada de Colón se irá convirtiendo en amarga denuncia ante la situación de los vencidos cuando se muestren las vejaciones sufridas por los indios (en espe- 
cial las de las indias que se ofrecen a los marineros) y, sobre todo, cuando se describa la simbólica revuelta final de los perros mudos, los «perrillos del Paraíso» que no temen a los «orgullosos mastines policiales» y que, a pesar de retirarse, deciden para siempre declararse «en rebeldía por vía de inacción» ${ }^{39}$. Apenas quedará tampoco lugar para ella al abordar este tema en la siguiente novela cuando Cabeza de Vaca, que reconoce en esta nueva crónica haber formado una familia entre los indios, ve también, ya en España, cómo su propio hijo, tratado como esclavo, se deja morir porque «no tenía ganas de nuestra civilización. No tenía espacio (...). Lo habíamos dejado sin mundo» ${ }^{40}$.

\section{VISITAR EL PASADO CON EL SENTI- DO DEL PRESENTE}

Distorsionar el material histórico, cuestionar la historia oficial, intentar ofrecer la otra cara de la conquista, utilizando para ello técnicas como la intertextualidad o la ironía, son los objetivos principales de Abel Posse en las tres novelas presentadas. $\mathrm{Y}$, sin embargo, el fin último del autor al concebirlas no es sólo comprender el pasado, sino hacerlo a la luz de su proyección en el presente.

Sin una relación vívida con el presente explica Lukács, la plasmación de la historia resulta imposible. Pero con respecto al arte histórico verdaderamente grande, esta relación no consiste en insinuaciones sobre algún acontecimiento coetáneo (...), sino en la revivificación del pasado convirtiéndolo en prehistoria del presente ${ }^{41}$.

A pesar de los diferentes planteamientos ideológicos que originan sus propuestas, el escritor argentino, al abordar en sus novelas esa etapa fundacional de la realidad latinoamericana que él define como la del «cubrimiento" de América, asume la tarea impuesta a la novela histórica por el teórico húngaro, como asume también el reto lanzado por Alejo Carpentier al escritor latinoamericano de «aceptar la muy honrosa condición de cronista mayor, Cronista de Indias, de nuestro mundo» ${ }^{42}$. La decisión (vinculada, como hemos visto, al contexto político en el que escribe el autor) de que Aguirre siga viviendo hasta el siglo XX, que se convierte en la base estructural de Daimón, se deriva del hecho de que esa «impronta anárquica y salvaje» que lo caracteriza es para Posse la que permanece en América ${ }^{43}$. Como él mismo ha explicado,

Nnsotros somos un continente violento, que todavía no alcanzó formas civiles y democráticas asentadas. Es en esas reflexiones donde interviene el análisis de nuestras raíces, y es precisamente la raíz de la conquista hispánica lo que nos lleva a una versión casi fascista del poder ${ }^{4}$.

El objetivo de Daimón es, pues, vincular ese periodo histórico con el presente de América Latina porque en definitiva, como ha señalado Fernando R. Lafuente, en todas las novelas de Posse «sólo existe el presente» ${ }^{45}$. La técnica para establecer este vínculo, tal vez más clara en esta obra que en las dos posteriores, revela ya los dos ejes sobre los que se va a fundar esta forma de revisión del pasado: el viaje como concepto y un peculiar tratamiento de las coordenadas temporales.

Por lo que atañe al primero de estos aspectos, es necesario destacar cómo los personajes del escritor argentino suelen ser, al igual que él mismo, viajeros. Domingo Luis Hernández ha explicado que, en el conjunto de la producción novelística de Posse,

...el viaje, el desplazamiento, la peregrinación, es más que un discurrir de la historia o en la historia, más que un ejercicio de interpretación, más que un ejercicio de imaginación: es la persecución de respuestas, el allanamiento de preguntas que un hombre condenado al movimiento se plantea. Es, en definitiva, un modo de reconocimiento ${ }^{46}$.

Aguirre emprende sucesivas jornadas que le llevan a conocerse a sí mismo, pero también a reconocer finalmente la realidad americana. Se trata de un viaje iniciático que parece recorrer el tiempo de forma lineal, en su progresión histórica, pero que en realidad, como expresa el autor al comienzo de la novela, se realiza «en el Eterno Retorno de lo Mismo, que es una espiral espacio-temporal». La obra se enmarca así en una concepción cíclica del tiempo, presidida por la idea de la muerte ${ }^{47}$, que es la que permite al autor en realidad no sólo visitar las distintas épocas de la historia americana, sino relacionarlas como diversas manifestaciones de lo Mismo.

Inicia así Abel Posse su propia manera de enfrentarse al pasado de América como origen del presente, que vuelve a manifestarse
39

Los perros del paraiso, pág. 222.

40

El largo atardecer del caminante, pág. 257.

41

Georg Lukács, La novela histórica, México, Ediciones Era, 1971, pág. 58.

42

Alejo Carpentier, La novela latinoamericana en vísperas de un nuevo siglo y otros ensayos, Madrid, Siglo XXI, 1981, pág. 240.

43

Véase La Semana de Autor sobre Abel Posse, op. cit., pág. 77.

44

Pites, "Entrevista a Abel Posse», op. cit., pág. 124.

45

La Semana de Autor sobre Abel Posse, op. cit., pág. 25.

46

En ibidem, pág. 37.

47

Ya que inicia con un Aguirre que regresa "de su combate nocturnal contra los muertos» (Daimón, pág. 14) y finaliza con la muerte definitiva de éste.
Daimón de Abel Posse: hacia una nueva crónica de América BEATRIZ ARACIL VARÓN 
48

En La Semana de Autor sobre Abel Posse, op. cit., pág. 65.

49

Los perros del paraíso, pág. 154.

50

El valor del viaje como forma de conocimiento es vital en esta obra en la que, como ha señalado Oscar Peyrou, «hay varios viajes: los que efectivamente cumple el personaje histórico, y el imaginario, el que hace a través de su memoria y que es el que, en definitiva, da forma a la novela (La Semana de Autor sobre Abel Posse, op. cit., pág. 79).

51

El largo atardecer del caminante, pág. 262.

52

Sáinz de Medrano, "Abel Posse y la búsqueda de lo absoluto", op. cit., pág. 467.

53

Daimón, págs. 167-178.

54

Ibidem, pág. 178.

55

Los perros del paraíso, pág. 214.

56

Ibidem, pág. 215. en Los perros del paraíso porque, como explica el autor,

...es evidente que el episodio del descubrimiento y la conquista de nuestro continente era un poco el Big Bang, no sólo para América, sino también para la propia Europa (...). Yo quise hacer presente el pasado, o si lo prefiere, visitar el pasado con el sentido del presente. De alguna manera, Colón y la reina Isabel siguen presentes en nuestra vida ${ }^{48}$.

La manera de visitar ese pasado es de nuevo la idea del viaje, pero no a través de una concepción cíclica sino, más bien, de una simultaneidad, de un «cruce de tiempos» como el que vive el propio Colón cuando

Por la rajadura del velo espacio-temporal empezaron a deslizarse seres, naves, escenas humanas, que el almirante tuvo, como buen visionario que era, que aceptar sin tratar de buscar explicaciones ${ }^{49}$.

Esta simultaneidad de tiempos favorece además el continuo uso del anacronismo, cuyo ejemplo más evidente son tal vez los signos que se atribuyen al reinado de los Reyes $\mathrm{Ca}$ tólicos (el uso de la svástica, el ejército de las SS, los perros guardianes alemanes...).

$\mathrm{El}$ anacronismo, como, en general, el libre tratamiento de las coordenadas temporales, aparece de forma mucho más sutil en la siguiente novela, en la que, sin embargo, continúa presente la fórmula del viaje a través del tiempo y del espacio ${ }^{50}$. Es cierto que, aparentemente, El largo atardecer del caminante rompe con la vinculación pasado-presente que se establece en las dos novelas anteriores; $\sin$ embargo, el final mismo de la obra, en el que el protagonista define su nueva crónica como «un mensaje arrojado al mar del tiempo» ${ }^{51}$, nos recuerda que en realidad sus reflexiones a lo largo de toda la novela son también una forma de revisar el pasado desde el presente de ese «buen lector» que hará que la obra no naufrague en el olvido.

\section{AMÉRICA: ANSIA, JUGO Y SANGRE}

La presencia del viaje, en las tres novelas estudiadas, como forma de conocimiento «histórico» a través del tiempo y del espacio, pero también como experiencia iniciática de cada uno de los protagonistas, nos lleva a plantear un último aspecto que tiene que ver precisa- mente con la manera en la que estos personajes, a pesar de no ser americanos, acceden a una verdadera «experiencia» de este continente.

Sáinz de Medrano ha definido el conjunto de la novelística de Abel Posse como un solo libro, «el libro de la ansiedad, la vehemente, desesperada o -si cabe el adjetivo- calculada ansiedad de unos seres que intentan superar sus propias vidas (...), dar el gran salto hacia lo que trasciende» ${ }^{52}$. Creo que en Daimón, como en Los perros del paraíso y El largo atardecer del caminante, esa ansiedad tiene que ver con la realidad misma americana hasta tal punto que es posible afirmar que, para el autor, lo Absoluto como objetivo de esa búsqueda, lo «Abierto» es América. La experiencia de sí mismo y del continente que tiene Aguirre en Machu Picchu ${ }^{53}$ se va a repetir, sin apenas variantes, en Colón respecto al Paraíso de las tierras caribeñas y en Cabeza de Vaca en el territorio tarahumara. A través de estas experiencias iniciáticas, los personajes acceden a una realidad distinta, lo que supone una transformación personal y un verdadero conocimiento de la América mítica. En Daimón, Aguirre es llevado por un guía espiritual indígena, Huamán, a una nueva dimensión a la que se accede por medio de una experiencia no racional, sino sensitiva. Ayudado por las sustancias alucinógenas que le proporciona el amauta, Aguirre se libera del «hacer», se «deshistoriza», para caer en el «estar». Este sentimiento de eternidad se identifica con un acceso a la «sudamericanidad» como posibilidad de acceso a lo "Abierto», al paraíso, que es la realidad mítica de América:

«¿Qué pasa, Huamán? ¿Qué es esto?». Y el amauta: «Son los colores del paraíso perdido (por ustedes) ${ }^{54}$

Esa misma sensación de estar «dentro del mundo, en el mundo, y no ante la realidad» ${ }^{55}$ es la que siente Colón en el Paraíso. En su caso «los hechiceros taínos juzgaron que no necesitaba drogas: su capacidad interna de secreción de delirio era perfecta", lo que le permite evitar por sí mismo «el embrutecimiento racionalista de los humanos» ${ }^{56}$. El resultado de su experiencia es de nuevo una transformación radical que tiene que ver con el conocimiento de América:

Resultaba evidente que el almirante había sufrido una mutación ya probablemente sin retorno (...). El 
río de pensamientos y ensueños que invadía al almirante también había tomado una coloración americana $^{57}$

Menos aventajado que Colón, Alvar Núñez deberá acudir, como Aguirre, a los guías indígenas, en esta ocasión los tarahumaras, quienes le proporcionan el Ciguri con el que será capaz de acceder al conocimiento pleno de la realidad mítica americana:

...vi raices por las que corría amarillo oro o maíz. Colores rotos, muy vivos, que sustituían objetos, planetas. Ideas de colores. Sentimientos fluyendo como agua (...). Comprendí que había viajado por avenidas de ciudades secretas. Que Marata o Totonteac bien podrían ser esas residencias indescriptibles a las que sólo se accede por el Ciguri, por la descomposición de todos los sentidos, con el viaje a lo transreals8.

La experiencia que supone ese «viaje a lo transreal» es la que permite comprender, además, por qué el personaje se define a sí mismo a partir de la transformación profunda que supone el contacto con la esencia de América cuando afirma: "Ya soy definitivamente otro (...). Soy el que vio demasiado ${ }^{59}$.

No cabe duda de que esta experiencia atribuida a los tres protagonistas tiene un correlato autobiográfico que explica, además, la importancia de Daimón en el conjunto de la novelística de Abel Posse: como ha explicado el propio autor,

...yo también descubrí América. Mi vida diplomática me llevó a vivir a Perú, y allí descubrí la América profunda, el universo indígena, la Historia de América y, también, al hilo de todo aquello, alli descubrí España. Sufro, pues, una transformación: yo era un escritor netamente argentino, al modo de como eran los escritores argentinos de la época: porteños, europeizantes, exclusivistas, y tuve una revelación de mi historia y de mi lenguaje ${ }^{60}$.

No es arbitraria, pues, la reiteración metafórica de esta experiencia vital y literaria en las tres novelas, ni la elección de Machu Picchu como el lugar donde se desarrolla el primero de estos viajes a la verdadera realidad del tiempo y el espacio. Pero creo que hay también una intencionalidad en la atribución de dicho viaje al personaje que encarna la barbarie de la conquista en esa novela que es, como ha señalado él mismo, la que refleja por primera vez la revelación de un nuevo lenguaje. Al hacer comprender al «monstruoso» Aguirre lo esencial americano, como lo harán después Colón y Alvar Núñez, Abel Posse nos sitúa, en definitiva, ante la posibilidad de cumplir la más deseada de sus utopías: el regreso al paraíso perdido, a esa América donde, como en el inicio de Daimón,

Todo es ansia, jugo, sangre, savia, jadeo, sístole y diástole, alimento y estiércol, en el implacable ciclo de leyes cósmicas que parecen recién establecidas ${ }^{61}$.

\section{BIBLIOGRAFÍA CITADA}

Carpentier, Alejo, La novela latinoamericana en vísperas de un nuevo siglo y otros ensayos, Madrid, Siglo XXI, 1981.

Colón, Cristóbal, Textos y documentos completos, ed. de Consuelo Varela, Madrid, Alianza, 1984.

Galster, Ingrid, « ¿oco o libertador? La imagen de Aguirre en la historiografía y la ficción: un proyecto de investigación», en Karl Kohut (ed.), De conquistadores y conquistados. Realidad, justificación, representación, Frankfurt am Main, Vervuert, 1992, págs. 256-271.

Galster, Ingrid, «El conquistador Lope de Aguirre en la nueva novela histórica», en Karl Kohut (ed.), La invención del pasado: la novela bistórica en el marco de la postmodernidad, Frankfurt-Madrid, Ed. Iberoamericana, 1997, págs. 196-204.

León-Portilla, Miguel, Crónicas indígenas. Visión de los vencidos, Madrid, Historia 16, 1985 [1 $1^{\text {a ed. }]} 1959$.

Lukács, Georg, La novela histórica, México, Ediciones Era, 1971, pág. 58.

Martínez Gómez, Juana, «Lope de Aguirre: historia y ficción», en AA. VV., Las relaciones literarias entre España e Iberoamérica, XXIII Congreso del Instituto Internacional de Literatura Iberoamericana, Madrid, Universidad Complutense, 1987, págs. 673-679.

Menton, Seymour, La nueva novela bistórica de América Latina, 1979-1992, México, Fondo de Cultura Económica, 1993.

Pastor, Beatriz, Discursos narrativos de la Conquista, Santiago, Casa de las Américas, 1983.

Pietri, Uslar, «El fuego fatuo», en 30 cuentos, Caracas, Monte Ávila Editores, 1969, págs. 73-79.
57

Ibid., págs. 214-215.

58

El largo afardecer del caminan†e, pág. 173.

59

Ibid., págs. 117-118.

60

Posse en La Semana de Autor sobre Abel Posse, op. cił., pág. 40.

61

Daimán, pág. 13. 
- «El peregrino», en La creación del Nuevo Mundo, Madrid, Mapfre, 1991, págs. 31-39.

- El camino de El Dorado, Buenos Aires, Losada, 1977.

Pites, Silvia, «Entrevista con Abel Posse», Chasqui, 22:2, (noviembre 1993, págs. 120-128).

Posse, Abel, «La novela como nueva crónica de América. Historia y mito», en Simposio Utopias del Nuevo Mundo, Praga, Charles U., 1993, págs. 258-265 y en Kohut, De conquistadores $y$ conquistados, op. cit., págs. 249-255.

- Daimón [1978], Barcelona, Plaza \& Janés, 1989.

- Los perros del paraíso, [1983], Barcelona, Plaza \& Janés, 1987.

- El largo atardecer del caminante [1992], Buenos Aires, Emecé, 1994.
Pulgarín Cuadrado, Amalia, Metaficción historiográfica: la novela bistórica en la narrativa hispánica postmodernista, Madrid, Fundamentos, 1995.

Sáinz de Medrano, Luis, (coord.), La Semana de Autor sobre Abel Posse, Madrid, Ediciones de Cultura Hispánica, 1997.

- «Abel Posse y la búsqueda de lo absoluto», Anales de Literatura hispanoamericana, Madrid, Universidad Complutense, $\mathrm{n}^{\circ} 21$, 1992, págs. 467-480.

Todorov, Tzvetan, La conquista de América. El problema del otro, Madrid, Siglo XXI, 1989.

Usábel González, Antonio Ángel, «Lope de Aguirre: la dominación del rebelde», en $\mathrm{La}$ novela histórica bispanoamericana: desde 1931 hasta nuestros dias, Universidad Autónoma de Madrid, 2000 (tesis doctoral) págs. 322-440. 